\title{
KONSENTRASI POLYCHLORINATED BIPHENYLS (PCBS) DAN POLYCHLORINATED DIBENZO-P-DIOXINS/POLYCHLORINATED DIBENZOFURANS (PCDDS/FS) DALAM AIR DARI DAERAH PERKOTAAN JABODETABEK
}

\section{Concentrations Of Polychlorinated Biphenyls (PCBs) And Polychlorinated Dibenzo-p-Dioxins/Polychlorinated Dibenzofurans (PCDDs/Fs) In Water Samples From Jabodetabek Urban Area}

\author{
Oleh : \\ Ahmad Shoiful ${ }^{1)^{*}}$, Rudi Nugroho ${ }^{1)}$, Hiroyuki Fujita ${ }^{2)}$, Katsuhisa Honda ${ }^{2)}$, \\ 1) Pusat Teknologi Lingkungan, Badan Pengkajian dan Penerapan Teknologi (BPPT), Indonesia \\ 2) Environmental Science for Industry Laboratory, Environmental Conservation Department, Faculty of \\ Agriculture, Ehime University, Japan
}

\begin{abstract}
Abstrak
Penentuan senyawa polychlorinated biphenyls (PCBs) dan polychlorinated dibenzo-p-dioxins and polychlorinated dibenzofurans (PCDDs/Fs) dalam sampel air dari daerah perkotaan di Jabodetabek, telah dilakukan. Di dalam hasilnya, suatu pola yang unik secara menarik ditemukan pada air sungai Ciliwung, Pluit, Jakarta, dimana decachlorinated biphenyl (PCB IUPAC \#209) dan dichlorinated biphenyI (PCB IUPAC \#11) terdeteksi dengan konsentrasi yang relative tinggi, yaitu masing-masing sebesar 406,77 $\mathrm{ng} / \mathrm{L}$ dan 6,38 $\mathrm{ng} / \mathrm{L}$. Pola kongener ini berbeda dengan campuran PCBs komersial, seperti arochlor, kanechlor maupun chlopen. Octachlorinated dibenzo-p-furan (OCDF) juga terdeteksi pada konsentrasi yang signifikan di dalam air tersebut, yaitu sebesar 3,10 ng/L. Decachlorinated biphenyl (PCB IUPAC \#209) dan OCDF dikaitkan dengan produk samping dari industri. Sementara itu, dichlorinated biphenyl (PCB IUPAC \#11) dikaitkan dengan pigmen warna yang secara luas digunakan dalam barang-barang konsumsi, seperti cat dan tinta printer. Sehingga kontaminasi PCB dan PCDD/Fs mungkin ditimbulkan dari produk samping industri yang berada sekitar titik pengambilan sampel.
\end{abstract}

Kata kunci: polychlorinated biphenyls (PCBs), polychlorinated dibenzodioxins /polychlorinated dibenzo-p-furans (PCDDs/Fs), air, Jabodetabek, produk samping industri.

\begin{abstract}
Determination of polychlorinated biphenyls (PCBs) and polychlorinated dibenzo-p-dioxins and polychlorinated dibenzofurans (PCDDs/Fs) in water samples from Jabodetabek urban area was conducted. In the results, a unique pattern were found interestingly in Ciliwung river, Pluit, Jakarta, where decachlorinated biphenyl (PCB IUPAC \#209), and dichlorinated biphenyl (PCB IUPAC \#11) were detected at relatively high concentrations as $406.77 \mathrm{ng} / \mathrm{L}$ and $6.38 \mathrm{ng} / \mathrm{L}$, respectively. This congener pattern is different with commercial PCB mixtures, such as arochlor, kanechlor, or chlophen. Octachlorinated dibenzo-p-furan (OCDF) was also detected at a significant concentration in this water as $3.10 \mathrm{ng} / \mathrm{L}$. Decachlorinated biphenyl (PCB IUPAC \#209) and OCDF were associated with industrial by-products. Meanwhile, dichlorinated biphenyl (PCB IUPAC \#11) was associated with colour pigment which widely used in consumer goods, such as paint and printed ink. Thus, PCBs and PCDD/Fs contamination might have arisen from industrial by-products where various industries located near sampling point.
\end{abstract}

Keywords: polychlorinated biphenyls (PCBs), polychlorinated dibenzodioxins /polychlorinated dibenzo-p-furans (PCDDs/Fs), waters, Jabodetabek, industrial by-products.

\section{PENDAHULUAN}

Polychlorinated biphenyls (PCBs) dan polychlorinated dibenzo-p-dioxins/polychlorinated dibenzofurans (PCDD/Fs) menjadi perhatian utama global karena mereka dapat ditemukan pada semua media lingkungan meskipun jauh dari sumber pencemaran. PCBs dan PCDD/Fs adalah kelompok senyawa Persistent Organic Pollutants (POPs) berdasarkan Konvensi Stockholm. Dalam tinjauan secara sederhana, senyawa POPs terdiri dari dua sumber utama, yaitu sengaja diproduksi dan tidak sengaja diproduksi sebagai produk samping dari proses industry atau pembakaran. Senyawa PCBs 
merupakan senyawa yang sengaja diproduksi secara komersial sebagai campuran pada aplikasi industri seperti pada cairan dielektrik pada kapasitor dan trafo, selain itu juga secara tidak sengaja terkandung sebagai impurities pada pelarut tinta, bahan plastic, dan cat (UNEP, 2001; Hu and Hornbuckle, 2010).

PCDD merupakan senyawa tidak sengaja diproduksi dari pembakaran tidak sempurna, proses produksi pestisida dan senyawa berklorin lainnya. Senyawa tersebut lepas ke lingkungan dari pembakaran terbuka dari sampah, sisa pertanian, industry logam dan limbah berbahaya (Gullet et al., 2010; Zhang et al., 2008; Wang et al., 2009; Wang et al., 2014). Sedangkan PCDF juga dihasilkan dari proses yang sama dengan proses yang menghasilkan PCDD, dan juga produksi PCBs.

Pada studi sebelumnya dilaporkan bahwa senyawa POPs terdeteksi pada sedimen, bahan makanan, dan juga air susu ibu (M.Ilyas et al., 2011; A. Shoiful et al., 2013, Sudaryanto et al., 2006). Namun sedikit informasi mengenai pencemaran senyawa POPs, khususnya PCBs dan PCDD/Fs dalam air di Indonesia, khususnya di area Jabodetabek. Sejak senyawa PCBs dan PCDD/Fs dapat ditimbulkan dari produksi tidak disengaja, selain itu juga jalur utama masuknya senyawa POPs ke dalam tubuh manusia adalah melalui makanan atau air minum, maka pemantauan keberadaannya di dalam air sangat dibutuhkan.

\section{Metode}

\subsection{Area Studi}

Studi ini mengambil lokasi di Jabodetabek, yang merupakan daerah yang paling padat penduduknya di Indonesia. Sebagai daerah perkotaan dan juga industri, sumber pencemaran yang utama adalah dari domestik dan juga industri.

\subsection{Pengambilan Dan Penyiapan Sampel}

Sampel air diambil dari lima titik di area Jabotabek pada bulan Agustus 2010, yaitu mulai dari air sumur di kawasan Puncak, Bogor, air sungai Ciliwung di Bogor sampai Pluit, Jakarta Utara, dan air sungai di daerah budidaya perikanan bandeng Kosambi, Tangerang (lihat pada Gambar 1).

Air sebanyak $500 \mathrm{~mL}$ dilewatkan pada kolom Sepabeads dan PS@Liq Autoprep, yang digunakan sebagai substrat untuk mengikat senyawa POPs. Kolom tersebut kemudian disimpan dalam kantong plastik tertutup "Zipfloc" dan suhu $-20{ }^{\circ} \mathrm{C}$ untuk kemudian dianalisis. Sedangkan sampel air yang diambil dari sungai Ciliwung, karena mengandung partikel yang tinggi, langsung diambil dan disimpan dalam botol. Seluruh sampel dikirim ke
Environmental Science for Industry Laboratory, Ehime University, Jepang untuk dianalisis.

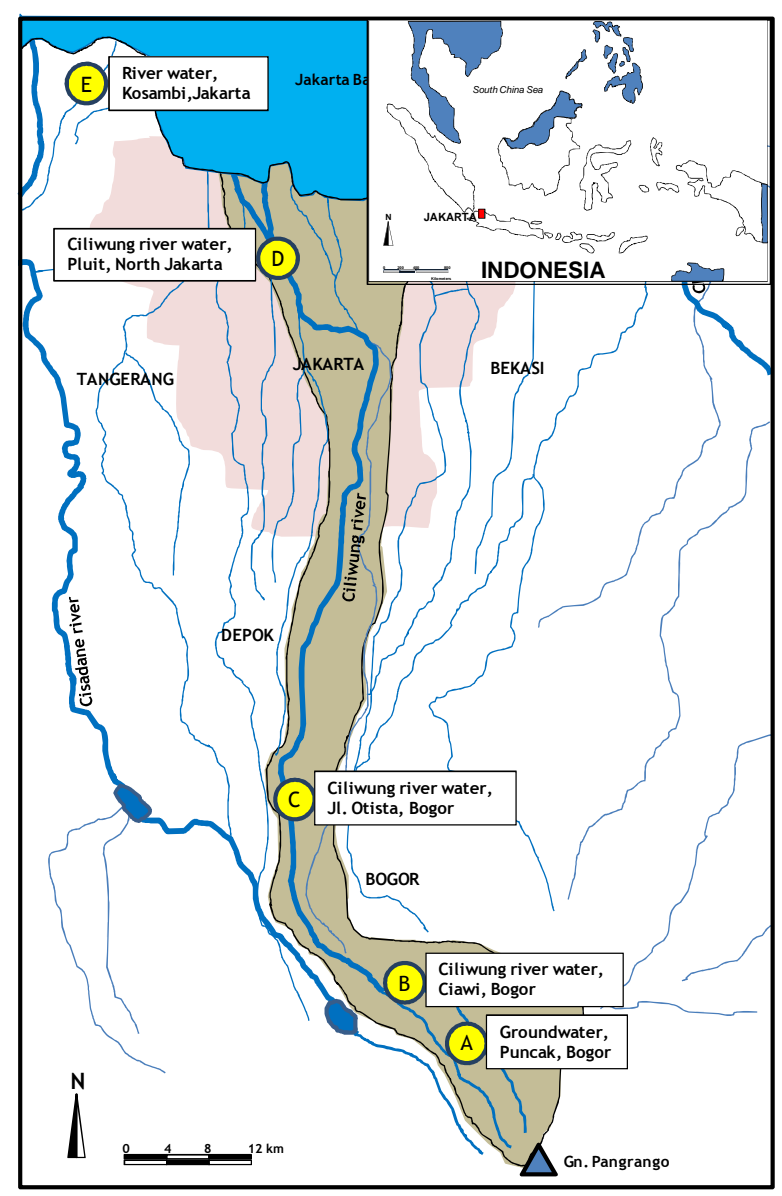

Gambar 1 : Lokasi Sampling Air di Area Jabodetabek.

\subsection{Metode Ekstraksi}

Kolom Sepabeads ${ }^{\circledR} /$ PS@Liq ${ }^{\circledR} \quad$ Autoprep dilewatkan dengan aseton $20 \mathrm{~mL}$ untuk fraksi pertama, dan kemudian heksan:diklorometan (1:1) $20 \mathrm{~mL}$ untuk fraksi kedua. Aseton pada fraksi pertama diekstraksi denga diklorometan yang hasilnya digabungkan dengan hasil dari fraksi kedua. Hasil ekstraksi tersebut kemudian dipurifikasi dengan kolom 10\% (w/w) silver nitrate-silica gel (3 g), dan dilewatkan dengan 10\% diklorometan:heksan $160 \mathrm{~mL}$ sebelum dianalisis dengan HRGC/HRMS.

Sedangkan untuk air yang diambil dari sungai Ciliwung, Pluit, ditambahkan dengan Dioflock $^{\circledR}$, reagen koagulan yang berfungsi untuk mengikat senyawa POPs, kemudian disaring dengan kertas saring. Untuk fase cair diekstraksi dengan metode ekstraksi liquid-liquid dengan pelarut diklorometan, sedangkan fase pada pada kertas saring diekstraksi dengan ekstraktor Soxhlet dengan pelarut toluene selama 16 jam. Hasil ekstraksi keduanya kemudian digabungkan dan kemudian dipurifikasi dengan 
kolom 10\% (w/w) silver nitrate-silica gel (3 g) dan dilewatkan dengan larutan diklorometan:heksan 160 $\mathrm{mL}$ sebelum dianalisis dengan HRGC/HRMS.

\subsection{Analisis dengan HRGC-HRMS}

\section{a. Polychlorinated biphenyls (PCBs)}

Polychlorinated biphenyls (PCBs) dianalisis dengan HRGC/HRMS (Hewlett Packard GC Agilent 6890 series ditandem dengan Mass Spectrometer JMS-700D dan JMS 800-D, JEOL Ltd, Japan) menggunakan kolom kapiler HT8-PCB. Suhu injector inlet diatur pada $220^{\circ} \mathrm{C}$. Suhu awal oven $30^{\circ} \mathrm{C}$, waktu awal 1 min, meningkat menjadi $180^{\circ} \mathrm{C}$ dengan laju 20 ${ }^{\circ} \mathrm{C}$ min $^{-1}$ dan kemudian $210{ }^{\circ} \mathrm{C}$ dengan laju $2{ }^{\circ} \mathrm{C} \mathrm{min}^{-1}$ dan $310{ }^{\circ} \mathrm{C}$ dengan laju $5{ }^{\circ} \mathrm{C}$ min $^{-1}$ dengan waktu final selama $3 \mathrm{~min}$. Gas helium ( $\mathrm{He}$ ) digunakan sebagai gas pembawa dengan laju alir $1.5 \mathrm{ml} \mathrm{min}^{-1}$. Suhu sumber ionisasi diatur pada suhu $280{ }^{\circ} \mathrm{C}$.

\section{b. Polychlorinated dibenzo-p-dioxins/furans (PCDDs/Fs)}

PCDDs/Fs dianalisis dengan HRGC/HRMS dilengkapi dengan kolom kapiler DB-5MS (J\&W scientific, Agilent), suhu oven awal diatur pada 150 ${ }^{\circ} \mathrm{C}$, waktu awal selama $1 \mathrm{~min}$, ditingkatkan menjadi $220{ }^{\circ} \mathrm{C}$ dengan laju $20{ }^{\circ} \mathrm{C} \mathrm{min}^{-1}$ kemudian menjadi 260 ${ }^{\circ} \mathrm{C}$ dengan laju $2{ }^{\circ} \mathrm{C} \min ^{-1}$ kemudian ditingkatkan menjadi $320{ }^{\circ} \mathrm{C}$ dengan laju $5{ }^{\circ} \mathrm{C} \mathrm{min}^{-1}$ dengan waktu final $3.5 \mathrm{~min}$ dan suhu sumber ionisasi diatur pada suhu $280{ }^{\circ} \mathrm{C}$.

\subsection{Quality Assurance/ Quality Control (QA/ QC)}

\section{a. Tes Blanko}

Prosedur pengetesan sampel blanko dilakukan untuk mengevaluasi interferenso dan kontaminasi. Hasil pengetesan menunjukkan tidak terdapat kontaminasi selama proses analisis, termasuk pada tahap ekstraksi, clean up, dan kuantifikasi..

\section{b. Recovery}

Recovery dari PCBs dan PCDD/Fs berada pada kisaran yang dapat diterima, yaitu masing-masing 78 $-119 \%$ and $91-118 \%$.

\section{c. Limit of Detection (LOD) dan Limit of Quantification (LOQ)}

Minimum limit of detection (LOD) dan minimum limit of quantification (LOQ) dihitung dengan 3-kali and 10-kali dari standar deviasi (STDEV) dari lima kali analisis standard PCBs dan PCDD/Fs.
LOD PCBs dan PCDD/Fs berada pada kisaran masingmasing 0.01-0.04 ng/L dan 0.001-0.015 ng/L.

\section{Hasil dan diskusi}

Analisis PCBs dan PCDD/Fs telah dilakukan terhadap lima sampel air yang diambil dari daerah perkotaan di Indonesia. Sampel air tersebut diambil dari air sumur, Puncak, Bogor (Water A), air sungai Ciliwung, Babakan, Ciawi, Bogor (Water $B$ ), air sungai Ciliwung, Jl. Otista, Bogor (Water C), air sungai Ciliwung, Pluit, Jakarta (water D), dan air sungai Kosambi, Tangerang (Water E). Hasil analisis menunjukkan bahwa ctachlorodibezofuran (OCDF) and decachlorobiphenyl (PCB IUPAC \#209) terdeteksi pada sampel water $D$ pada konsentrasi yang relatif tinggi yaitu masing-masing sebesar $3,11 \mathrm{ng} / \mathrm{L}$ dan 406,77 ng/L. Hasil selengkapnya konsentrasi PCBs dan PCDDs/Fs dalam air di Indonesia dapat dilihat pada Tabel 1 (di lampiran), sedangkan profil kongener dichlorobiphenyl dalam sampel D (Water D) dapat dilihat pada Gambar 2 (lampiran).

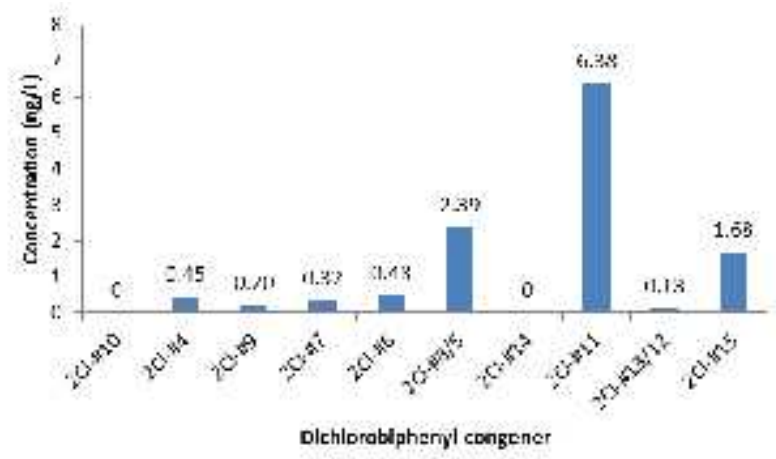

Gambar 2: Profil kongener dichlorobiphenyl dalam sampel Water D.

Decachlorobiphenyl (PCB IUPAC \#209) terdeteksi dengan konsentrasi tertinggi (406.77 $\mathrm{ng} / \mathrm{L})$. Konsentrasi tinggi yang tidak biasa dari decachlorinated biphenyl (PCB IUPAC \#209) juga dilaporkan pada studi sebelumnya, dimana decachlorinated biphenyl (PCB IUPAC \#209) dengan konsentrasi tinggi terdapat pada padatan tersuspensi sungai Delaware, yang kemungkinan berasal dari pabrik purifikasi titanium dioksida yang berlokasi di dekat sungai tersebut (Rowe et al., 2007). Decachlorinated biphenyl (PCB IUPAC \#209) juga merupakan kongener yang ditemukan berlebih pada fasa partikulat baik di udara dan air hujan di Galveston Bay, Texas, USA (Park et al, 2001). Ishikawa et al (2007) melaporkan bahwa decachlorinated biphenyl (PCB IUPAC \#209) dihasilkan dari pembakaran hasil pencacahan mobil bekas (Automobile Shredder Residue). Konsentrasi yang relative tinggi juga ditemukan pada air dan sedimen 
Houston Ship Chanel, Texas, USA (Howell et al., 2008), yang mungkin berasal dari produk Fenclor DK atau Aroclor 1271, yang sebagain besar berisi decachlorobiphenyl (PCB IUPAC \#209) (Howell et al., 2011).

Decachlorobiphenyl (PCB IUPAC \#209) dan hexachlorobenzene merupakan senyawa impurities pada teknikal klorothalonil (FAO, 2007). Klorothalonil secara digunakan sebagai fungisida utama pada kacang, kentang, tomat dan juga pada lapangan golf, selain itu juga digunakan sebagai bahan tambahan pada cat, resin, emulsi dan coating (EPA, 1999). Konsentrasi tinggi decachlorinated biphenyl (PCB IUPAC \#209) pada sampel water D menunjukkan bahwa potensi sumber pencemaran adalah dari produk samping industri.

Studi ini juga menunjukkan bagian yang cukup tinggi dari dichlorinated biphenyls (PCB IUPAC \#11). Konsentrasi dichlorinated biphenyls (PCB IUPAC \#11) ditemukan paling tinggi pada sampel water $D$ sebesar $6.38 \mathrm{ng} / \mathrm{L}$. Studi sebelumnya melaporkan bahwa dichlorinated biphenyls (PCB IUPAC \#11) ditemukan pada limbah cair dari fasilitas pabrik cat, dan juga azo, phthalocyanine dan pigmen kuning diarylide, yang umum digunakan pada cat, tinta, tekstil, kertas, plastic dan material lainnya (Rodenburg et al., 2010; $\mathrm{Hu}$ and Hornbuckle, 2010; Shang et al., 2014). Dichlorinated biphenyls (PCB IUPAC \#11) juga ditemukan di pelabuhan NJ/NY dan sungai Delaware, USA, yang mungkin ditimbulkan dari produk konsumsi, seperti kertas dan material cardboard (Rodenburg et al., 2010). Selain itu, pola profil kongener yang ditemukan di water $D$ berbeda dengan profil homolog PCBs yang ada di dalam komersial PCBs Kanechlor, dimana didominasi oleh tetrachlorinated biphenyls (T4CB), kemudian diikuti oleh T3CBs/P5CBs/H6CBs (Takasuga et al., 2006). Jadi, keberadaan dichlorinated biphenyls (PCB IUPAC \#11) di sungai Ciliwung, Pluit, Jakarta kemungkinan berasal dari proses industri yang menggunakan zat pigmen warna, bukan dari komersial produk PCBs. Beberapa industri percetakan berada di sekitar lokasi titik sampling.

PCDD/Fs juga ditemukan pada sampel water D dan water E. 1,2,3,4,6,7,8-heptachlorodibenzofuran (HpCDF) dan octachlorodibezo-p-furan (OCDF) terdeteksi pada water $D$ dengan konsentrasi masingmasing sebesar $0.010 \mathrm{ng} / \mathrm{L}$ and $3.10 \mathrm{ng} / \mathrm{L}$. Sedangkan 1,3,6,8-tetrachloro dibenzo-p-dioxin (TCDD) dan octachlorodibenzo-p-dioxin (OCDD) terdeteksi pada water $\mathrm{E}$ dengan konsentrasi sebesar $0.008 \mathrm{ng} / \mathrm{L}$ dan $0.060 \mathrm{ng} / \mathrm{L}$. konsentrasi yang realtif tinggi OCDF juga ditemukan di sedimen Danau Ontario, Kanada (Shen et al., 2008) dan Danau Huron, Canada (Shen et al., 2009), yang kemungkinan ditimbulkan dari pabrik klorin dan bahan kimia berklorin lainnya yang berlokasi di sepanjang daerah aliran sungai Niagara dan juga terkait dengan industry pulp dan kertas serta pengolahan kayu yang menggunakan pentakloropenol (PCP).

Teknikal pentakloropenol biasanya mengandung beberapa bahan toksik sebagai impuritas seperti polychlorinated dibenzodioxins (PCDDs) dan polychlorinated dibenzo-p-furans (PCDFs). Senyawa-senyawa tersebut terdapat pada proses manufaktur PCP, dimana octachlorinated dibenzo-p-dioxin (OCDD) dan octachlorinated dibenzofuran (OCDF) merupakan produk yang dominan (Qian et al, 2005). Tondeur et al. (2010) melaporkan bahwa OCDD dan OCDFditemukan pada konsentrasi yang cukup tinggi dan OCDF merupakan kongener yang dominan dari PCDD/Fs berdasarkan berat yang terdapat pada produksi PCP, diikuti oleh heptachlorinated (HpCDD/Fs) dan hexachlorobenzene (HCB). PCP adalah herbisida dan banyak digunakan sebagai bahan pengawet kayu (fungisida) dan digunakan industri pengawetan kayu untuk bantalan rel kereta api, tiang listrik dan tiang dermaga (ATSDR, 2001). Ratnaningsih et al. (2002) melaporkan bahwa PCP terdeteksi di sungai Ciliwung, Jakarta pada kisaran 0,21-6,09 ng/L. Namun demikian, tidak ada informasi tentang produksi dan penggunaan PCP di Indonesia.

Beberapa senyawa berklorin juga teridentifikasi dengan mode full scan pada sampel water D, yaitu antara lain hexachlorofulvene and octachlorostyrene (OCS) (lihat Gambar 3). Chu et al., (2003) melaporkan bahwa OCS and hexachlorobenzene (HCB) terdeteksi pada tanah yang belokasi di dekat pabrik pembuat pestisida, dan kemungkinan dihasilkan sebagai produk samping bahan kimia. Hexachlorofulvene merupakan senyawa isomer struktural dari benzene. Hexachlorofulvene dan OCS dapat dihasilkan dari pembakaran trichloroetylene (TCE) dan campuran methane (Villalobos, et al., 1996).

Konsentrasi yang signifikan dari OCDF, deca-CB (PCB IUPAC \#209), serta teridentifikasinya hexachlorofulvene dan OCS dalam sampel water D mengindikasikan bahwa sumber pencemaran potensial adalah dari lepasan produk samping dari proses industri, dimana banyak industri yang berlokasi di dekat titik pengambilan sampel. Namun demikian, untuk mengklarifikasi dan memperoleh sumber pencemaran yang lebih akurat, maka penambahan titik sampel sangat diperlukan.

Sedangkan hasil analisis sampel water $E$ menunjukkan bahwa 1,3,6,8-TeCDD dan octachlorodibenzo-p-dioxin (OCDD) terdeteksi pada sampel tersebut. PCDD/Fs dapat dihasilkan dari pembakaran sampah domestic, seperti plastic, ban, limbah elektronik dan limbah peralatan rumah tangga (C.R Estrellan and F. lino, 2010; UNEP, 1999). 
OCDD menjadi kongener yang dominan dalam sampel water E tersebut. Gullet et al. (2010) melaporkan bahwa OCDD merupakan kongener yang utama dari emisi pembakaran terbuka yang diikuti dengan heptachloro dibenzo-p-dioxin (hepta-CDD). Di area dekat lokasi pengambilan sampel water $E$, terdapat pembakaran timbunan sampah domestic. Sehingga dengan hasil tersebut mengindikasikan bahwa pencemaran PCDD/Fs kemungkinan berasal dari proses pembakaran limbah domestic tersebut.

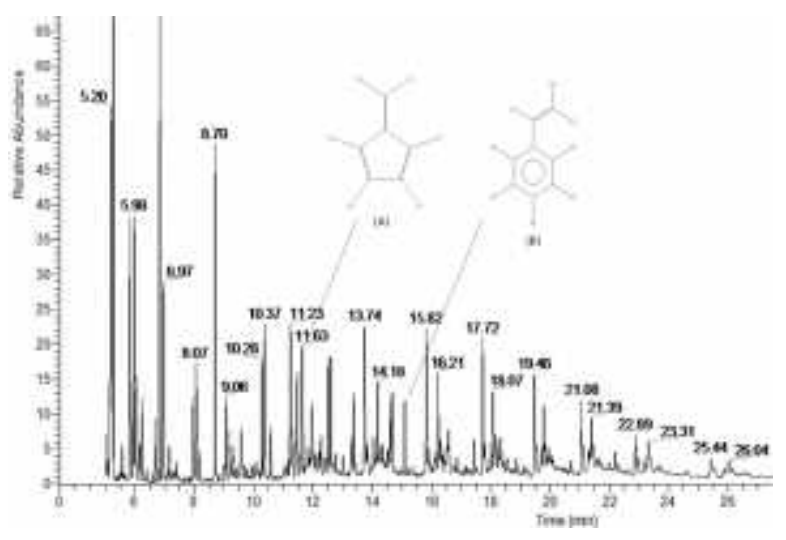

Gambar 3. Mode full scan kromatogram sampel water $D,(A)$ hexachlorofulvene, $(B)$ octachlorostyrene.

Bila dibandingkan dengan beberapa negara lain, maka PCBs dan PCDD/Fs di sungai Ciliwung lebih tinggi dibandingkan dengan delta sungai Pearl, estuary sungai Dalio di China dan sungai Ballona, Los Angeles, USA (Guan et al., 2009; Chen et al., 2011; Tan et al., 2009; Curren et al., 2011). Dan bila dibandingkan dengan hasil penelitian sebelumnya yang dilakukan oleh Iwata et al., (1994), PCBs di sungai Ciliwung meningkat. Hasil ini menunjukkan bahwa kemungkinan pencemaran terhadap lingkungan masih berlangsung. PCBs maupun PCDD/Fs dihasilkan dari produk samping dari proses industri, maka kemungkinan lepasan senyawa tersebut akan meningkat di masa yang akan datang bila tidak ada tindakan pencegahan dan pengurangan. The United Nation Environment Programme (UNEP) telah mengeluarkan panduan Penerapan Teknik Terbaik yang Tersedia dan Praktek Lingkungan yang Terbaik (Best Available Technique and Best Environmental Practice) yang menjadi alternatif cara untuk mengurangi lepasan $\mathrm{PCBs}$ dan PCDD/Fs ke lingkungan.

Konsentrasi PCBs dan PCDD/Fs dalam air di Indonesia dibandingkan dengan beberapa negara lain dapat dilihat pada Tabel 2 (di lampiran).

\section{KESIMPULAN}

Hasil studi ini menyediakan status PCBs dan PCDD/Fs dalam air di Indonesia, khususnya di area Jabodetabek. Hasil yang menarik didapatkan bahwa decachlorinated biphenyls (PCB IUPAC \#209) dan octachlorinated dibenzo-p-furan (OCDF) terdeteksi dengan konsentrasi yang relative cukup tinggi di dalam air sungai Ciliwung, Pluti, Jakarta. Lebih lanjut lagi, dichlorinated biphenyls (PCB IUPAC \#11) juga terdeteksi dalam konsentrasi yang cukup signifikan. Hasil ini menunjukkan bahwa sumber pencemaran air kemungkinan berasal hasil produk samping dari proses industry. Namun demikian, penambahan jumlah titik pengambilan sampel sangat diperlukan untuk mengklarifikasi hasil tersebut secara akurat.

\section{DAFTAR PUSTAKA}

- ATSDR. 2001. Toxicological profile for Pentachlorophenol. Agency for Toxic Substances and Disease Registry: Atlanta.

- Bailey, Robert E. 2001. Global hexachlorobenzene emission. Chemosphere 43: $167-182$.

- $\quad$ Chen, W., Jing, M., Bu, J., Burnet, J. E., Qi, S., Song, Q. 2011. Organochlorine pesticides in the surface water and sediments from the Peacock River Drainage Basin in Xinjiang, China: a study of an arid zone in Central Asia. Environ. Monit. Assess., 177: 1-21.

- Chu Shaogang, Adrian Covaci, Stefan Voorspoels and Paul Scephens. 2003. The distribution of octachlorostyrene (OCS) in environmental samples from Europe. J. Environ. Monit. 5: 619625.

- $\quad$ Curren Jane, Steven Bush, Simon Ha, Michael K. Stenstrom, Sim-Lin Lau, IH Mel Suffet. 2011. Identification of subwatershed sources for chlorinated pesticides and polychlorinated biphenyls in the Ballona Creek watershed. Sci. Total Environ. 409:2525-2533.

- Darko Godfred, Osei Akoto, Caleb Oppong. 2008. Persistent organochlorine pesticide residues in fish, sediments and water from Lake Bosomtwi, Ghana. Chemosphere 72: 21-24.

- Environmental Management Center (EMC). 2003. Monitoring of persistent organic pollutants (POPs) in the coastal hydrosphere of Indonesia. Country report UNU: Japan.

- Environmental Protection Agency (EPA). 1999. Reregistration Eligibility Decision (RED): Chlorothalonil. United States Environmental Protection Agency (US EPA) : Washington DC. 
- Estrellan, C.R., and lino, F., 2010. Toxic emission form open burning. Chemosphere 80, 193 207.

- Fair Patricia A., Jeff Adams, Gregory Mitchum, Thomas C. Hulsey, John S. Reif, Magali Houde, Derek Muir, Ed Wirth, Dana Wetzel, Eric Zolman, Wayne McFee, Gregory D. Bossart. 2010. Contaminant blubber burdens in Atlantic bottlenose dolphins (Tursiops truncatus) from two Southeastern US estuarine areas : Concentrations and pattern of PCBs, pesticides, PBDEs, PFCs, and PAHs. Sci. Total Environ. 408: 1577-1597.

- FAO. 2007. FAO specifications and evaluations for agricultural pesticides "Chlorothalonil: tetrachloroisophthalonitrile. Food and Agriculture Organization of the United Nation.

- Guan Yu-Feng, Ji-Zhong Wang, Hong-Gang Ni, Eddy Y. Zeng. 2009. Organochlorine pesticides and polychlorinated biphenyls in riverine run off of the Pearl River Delta, China: Assessment of mass loading, input source and environmental fate. Environ. Pollution 157:618-624.

- Gullet Brian K., Barbara Wyrzykowska, Emanuela Grandesso, Abderrahmanetouati, Dennis G. Tabor, Gustavo Solorzano Ochoa. 2010. PCDD/D, PBDD/F, and PBDE emissions from open burning of a residential estate dump. Environ. Sci. Technol. 44: 394-399.

- Howell, Nathan L., Monica P. Suarez, Hanadi S. Rifai, Larry Koenig. 2008. Concentration of polychlorinated biphenyls (PCBs) in water, sediments and aquatic biota in the Houston Ship Channel, Texas. Chemosphere 70: 593-606.

- Howell, Nathan L., Hanadi S. Rifai, Larry Koenig. 2011. Comparative distribution, sourcing, and chemical behavior of PCDD/Fs and PCBs in an estuary environment. Chemosphere 83: 873881.

- Hu, D. and Hornbuckle, K., 2010. Inadvertent polychlorinated biphenyls in commercial paint pigments. Environ. Sci. Technol. 44: 2822 2827.

- Ilyas Muhammad, Agus Sudaryanto, Iwan Eka Setiawan, Adi Slamet Riyadi, Tomohiko Isobe, Shin Takahashi, Shinsuke Tanabe. 2011. Characterization of polychlorinated biphenyls and brominated flame retardants in sediments from riverine and coastal waters of Surabaya, Indonesia. Marine Poll. Bull. 62: 89-98.

- Ishikawa Y., Yukio Noma, Takashi Yamamoto, Yoshihito Mori, Shin-ichi Sakai. 2007. PCB decomposition and formation in the thermal treatment plant equipment. Chemosphere 67 : 1383-1393.
- Iwata,H., Tanabe,S., Sakai,N., Nishimura,A. and Tatsukawa,R. 1994. Geographical distribution of persistent organochlorines in air, water and sediments from Asia and Oceania,

- and their implications for global redistribution from lower latitudes. Environmental Pollution.

- 85, 15

- Hitoshi Kakimoto, Hideo Oka, Yoshiaki Miyata, Yumiko Yonezawa, Akiko Niikawa, Hirohisa Kyudo, Ning Tang, Akira Toriba, Ryoichi Kizu, Kazuichi Hayakawa. 2006. Homologue and isomer distribution of dioxins observed in water samples collected from Kahokugata Lagoon and inflowing rivers, Japan. Water Research 40:1929 $-1940$.

- Bloksom Karen A., David M. Walters, Terri M. Jicha, James M. Lazorchak, Theodore R. Angradi and David W. Bolgrien. 2010. Persistent organic pollutans in fish tissue in the mid-continental great rivers of the United States. Sci. Total Environ. 408: 1180-1189.

- Lakshmanan D, Howell NL, Rifai HS, Koenig L. 2010. Spatial and temporal variation of polychlorinated biphenyls in the Houston Ship Channel. Chemosphere 80:100-12.

- $\quad$ Liu Y, Peng P, Li X, Zhang S, Ren M. 2008. Polychlorinated dibenzo-p-dioxins and dibenzofurans (PCDD/Fs) in water and suspended particulate matter from the Xijiang River, China. J. Hazard Mater 152 (1): 40-47.

- Oliveira Tiago, Gregory Santacroce, Richard Coleates, Stephen Hale, Paula Zevin, Barbara Belasco. 2011. Concentrations of polychlorinated biphenyls in water from US Lake Ontario tributaries between 2004 and 2008. Chemosphere 89: 1314-1320.

- Park J.S., Terry L.W., Stephen S. 2001. Atmospheric deposition of organochlorine contaminants to Galveston Bay, Texas. Atmospheric Environ. 35: 3315-3324.

- Qian Yong, Minghui Zheng, Wenbin Liu, Xiaodong Ma, Bing Zhang. 2005. Influence of Metal Oxides on PCDD/Fs Formation from Pentachlorophenol. Chemosphere 60: 951-958.

- Ratnaningsih, D., Helmy M., Bagus B.E., Nety W., Heni P. 2002. A survey on water pollution by endocrine disrupter compounds: Monitoring of organochlorine pesticides, phenols and phthalates in the coastal hydrosphere of Indonesia. Country report UNU: Japan.

- Roach AC, Muller, R, Komarova, T, Symons, R, Stevenson, GJ Mueller, JF. 2009. Using SPMDs to monitor water column concentrations of PCDDs, PCDFs and dioxin-like PCBs in Port Jackson 
(Sydney Harbour), Australia. Chemosphere 75:1243-1251.

- $\quad$ Rowe A.A., Lisa A. Totten, Mingexie, Thomas J. Fikslin, Stephen J.E., 2007. Air-Water Exchange of polychlorinated biphenyls in the Delaware River. Environ. Sci. Technol. 41 : 1152-1158.

- Rodenburg, L. A., Guo J., Du, S., Cavallo, G. J., 2010. Evidence for unique and ubiquitous environmental sources of 3,3'-Dichlorobiphenyl (PCB 11). Environ. Sci. Technol. 44 : 2816 2821.

- $\quad$ Rossi L1, de Alencastro L, Kupper T, Tarradellas J. 2004. Urban stormwater contamination by polychlorinated biphenyls (PCBs) and its importance for urban water systems in Switzerland. Sci Total Environ. 322:179-89.

- $\quad$ Shang Hongtao, Yingming Li, Thanh Wang, Pu Wang, Haidong Zhang, Qinghua Zhang, Guibin Jiang. 2014. The presence of polychlorinated biphenyls in yellow pigment products in China with emphasis on 3,3'-dichlorobiphenyl (PCB 11). Chemosphere 98:44-50.

- $\quad$ Shen Li, Sarah B. Gewutz, Eric J. Reiner, Karen A. MacPherson, Terry M. Kolic, Paul A. helm, Ian D. Brindle, Chris H. Marvin. 2008. Pattern and sources of polychlorinated dibenzo-p-dioxins and polychlorinated dibenzofurans in surficial sediments of Lakes Erie and Ontario. Environ. Pollut. 156 : 515-525.

- Shen Li, Sarah B. Gewurtz, Eric J. Reiner, Karen A. Macpherson, Terry M. Kolic, Vin Khurana, Paul A. Helm, E. Todd Howell, Debbie A. Burniston, Ian D. Brindle, Chris H. Marvin. 2009. Occurence and sources of polychlorinated dibenzo-p-dioxins, dibenzofurans and dioxin-like polychlorinated biphenyls in surficial sediments of Lakes Superior and Huron. Environ. Pollut. 157 : 1210-1218.

- Sudaryanto Agus, Tatsuya Kunisue, Natsuko Kajiwara, Hisato Iwata, Tussy A. Adibroto, Phillipus Hartono, Shinsuke Tanabe. 2006. Specific accumulation of organochlorines in human breast milk from Indonesia: Levels, distribution, accumulation kinetics and infant health risk. Environ. Pollut. 139:107 - 117.

- Shoiful, Ahmad, Hiroyuki Fujita, Isao Watanabe, Katsuhisa Honda. 2013. Concentrations of organochlorine pesticides (OCPs) residues in foodstuffs collected from traditional markets in Indonesia. Chemosphere 90:1742-1750.

- Sudaryanto A., Monirith I., Kajiwara N., Takahashi S., Philippus H., Muawanah, Omori K., Hidetaka T., Shinsuke T. 2007. Levels and distribution of organochlorines in fish from Indonesia. Environ. Int. 33:750-758.
- Takasuga, Takumi, Kurunthachalam Senthilkumar, Tohru Matsumura, Ken Shiozaki, Shin-ichi Sakai. 2006. Isotope dilution analysis of polychlorinated biphenyls (PCBs) in transformer oil and global commercial PCB formulations by high resolution gas chromatography-high resolution mass spectrometry. Chemosphere 62:469-484.

- Tan, L., He, M.C., Men, B., Lin, C.Y., 2009. Distribution and sources of organochlorine pesticides in water and sediments from Daliao River estuary of Liaodong Bay, Bohai Sea (China). Estuarine, Coastal and Shelf Science 84, 119-127.

- Tondeur Yves, Terry Nestrick, Hector A. Silva, Bryan Vining, Jerry Hart. 2010. Analytical procedures for the determination of polychlorinated-p-dioxins, polychlorinated dibenzofurans, and hexachlorobenzene in pentachlorophenol. Chemosphere 80: 157-164.

- Ueno D., T. Isobe, K. Ramu, S. Tanabe, M. Alaee, C. Marvin, K. Inoue, T. Someya, T. Miyajima, H. Kodama, H. Nakata. 2010. Spatial distribution of hexachlorocyclododecanes (HBCDs), polybrominated diphenyl ethers (PBDEs) and organochlorines in bivalves from Japanese coastal waters. Chemosphere 78 : 1213-1219.

- UNEP. 1999. Dioxin and furan inventories. National and regional emission of PCDD/PCDF. United Nation Environment Programme (UNEP), Switzerland : Geneva.

- UNEP, 2001. Stockholm Convention on Persistent Organic Pollutants (POPs), Interim Secretariat for the Stockholm Convention, United Nations Environmental Programmer (UNEP) Chemicals: Geneva, Switzerland; <http://www.pops.int>.

- UNEP. 2002. Regionally Based assessment of Persistent toxic substances: South East Asia and South Pacific Regional Report. Global Environment Facility, Switzerland: Geneva.

- Villabos S. Alex, Michael J. Anderson, Michael S. Denison, David E. Hinton, Katherine Tullis, Ian M. Kennedy, A. Daniel Jones, Daniel P. Y. Chang, Gosu Yang, Peter kelly. 1996. Dioxinlike properties of a Trichloroethylene combustiongenerated aerosol. Environ. Health Persp. 104 : 734-743.

- Wang, J.B., Chung-Hsien Hung, Chung-Hsuang Hung, Guo-Ping Chang-Chien. 2009. Polychlorinated dibenzo-p-dioxin and dibenzofuran emissions from an industrial park clustered with metallurgical industries. J Hazard Mater 161:800-807.

- Wang Qi, Yuqi Jin, Xiaodong Li, Jia Chen, Shengyong Lu, Tong Chen, Jianhua Yan, 
Miaosheng Zhou, Hua Wang. 2014. PCDD/F Emissions from Hazardous Waste Incinerators in China. Aerosol and Air Quality Research 14: 1152-1159.

- You Hong, Jing Ding, Xue-Song Zhao, Yi-Fan Li, Li-Yan Liu, Wan-Li Ma, Hong Qi, Ji-Min Shen. 2010. Spatial and seasonal variation of polychlorinated biphenyls

- in Songhua River, China. Environ Geochem Health 33, 291-299.
- Zhang Qing, Jun Huang, Gang Yu. 2008. Polychlorinated dibenzo-p-dioxins and dibenzofurans emissions from open burning of crop residues in China between 1997 and 2004. Environ Pollut 151:39-46. 
Tabel 1 : Konsentrasi PCBs dan PCDDs/Fs Dalam Air Dari Area Jabodetabek (ng/L)

\begin{tabular}{|c|c|c|c|c|c|}
\hline Isomer & Water A & Water B & Water C & Water D & Water E \\
\hline \multicolumn{6}{|l|}{ PCDD/PCDF } \\
\hline 1,3,6,8-TeCDD & ND & ND & ND & ND & 0.0080 \\
\hline 1,3,7,9-TeCDD & ND & ND & ND & ND & ND \\
\hline $2,3,7,8-\mathrm{TeCDD}$ & ND & ND & ND & ND & ND \\
\hline 1,2,3,7,8-PeCDD & ND & ND & ND & ND & ND \\
\hline $1,2,3,4,7,8-H x C D D$ & ND & ND & ND & ND & ND \\
\hline $1,2,3,6,7,8-\mathrm{HxCDD}$ & ND & ND & ND & ND & ND \\
\hline $1,2,3,7,8,9-\mathrm{HxCDD}$ & ND & ND & ND & ND & ND \\
\hline $1,2,3,4,6,7,8-\mathrm{HpCDD}$ & ND & ND & ND & ND & ND \\
\hline OCDD & ND & ND & ND & ND & 0.060 \\
\hline Total PCDDs & ND & ND & ND & ND & 0.068 \\
\hline $1,2,7,8-\mathrm{TeCDF}$ & ND & ND & ND & ND & ND \\
\hline $2,3,7,8-\mathrm{TeCDF}$ & ND & ND & ND & ND & ND \\
\hline $1,2,3,7,8-\mathrm{PeCDF}$ & ND & ND & ND & ND & ND \\
\hline $2,3,4,7,8+1,2,3,6,9-\mathrm{PeCDF}$ & ND & ND & ND & ND & ND \\
\hline $1,2,3,4,7,8-\mathrm{HxCDF}$ & ND & ND & ND & ND & ND \\
\hline $1,2,3,6,7,8-\mathrm{HxCDF}$ & ND & ND & ND & ND & ND \\
\hline $1,2,3,7,8,9+1,2,3,4,8,9-\mathrm{HxCDF}$ & ND & ND & ND & ND & ND \\
\hline $2,3,4,6,7,8+1,2,3,6,8,9-\mathrm{HxCDF}$ & ND & ND & ND & ND & ND \\
\hline $1,2,3,4,6,7,8-\mathrm{HpCDF}$ & ND & ND & ND & 0.010 & ND \\
\hline $1,2,3,4,7,8,9-\mathrm{HpCDF}$ & ND & ND & ND & ND & ND \\
\hline OCDF & ND & ND & ND & 3.10 & ND \\
\hline Total PCDFs & ND & ND & ND & 3.11 & ND \\
\hline Total PCDDs + PCDFs & ND & ND & ND & 3.11 & 0.068 \\
\hline \multicolumn{6}{|l|}{ PCBs } \\
\hline $1 \mathrm{Cl}$ & ND & ND & ND & 2.20 & 0.17 \\
\hline $2 \mathrm{Cls}$ & 0.087 & 0.098 & 0.11 & 12.03 & 1.99 \\
\hline $3 \mathrm{Cls}$ & ND & 0.026 & ND & 9.13 & 1.18 \\
\hline $4 \mathrm{Cls}$ & 0.012 & 0.013 & 0.011 & 23.34 & 1.53 \\
\hline $5 \mathrm{Cls}$ & ND & ND & ND & 4.74 & 0.41 \\
\hline $6 \mathrm{Cls}$ & ND & ND & ND & 1.77 & 0.18 \\
\hline $7 \mathrm{Cls}$ & ND & 0.014 & 0.011 & 1.17 & 0.035 \\
\hline $8 \mathrm{Cls}$ & ND & ND & ND & ND & ND \\
\hline $9 \mathrm{Cls}$ & ND & ND & ND & 0.48 & ND \\
\hline $10 \mathrm{Cls}$ & ND & ND & ND & 406.77 & ND \\
\hline Total-PCBs & 0.099 & 0.15 & 0.13 & 461.64 & 5.49 \\
\hline
\end{tabular}


Tabel 2 : Konsentrasi PCBs dan PCDD/Fs Dalam Air di Indonesia Dibandingkan dengan Negara-Negara Lain (ng/L)

\begin{tabular}{|c|c|c|c|c|c|}
\hline Negara & $\begin{array}{c}\text { Tahun } \\
\text { pengambilan } \\
\text { sampel }\end{array}$ & Lokasi & $\Sigma \mathrm{PCBS}$ & $\Sigma \mathrm{PCDD} / \mathrm{Fs}$ & Referensi \\
\hline \multirow[t]{2}{*}{ Indonesia } & 2010 & Ciliwung River & $0.13-461.64$ & ND-3.11 & Penelitian ini \\
\hline & 1991 & Ciliwung River & $0.38-2.1$ & NA & Iwata et al., 1994 \\
\hline \multirow[t]{5}{*}{ China } & $2005-2006$ & Xijiang River & NA & $0.02-0.073$ & Liu et al., 2008 \\
\hline & $2005-2006$ & Pearl River Delta & $0.12-1.47^{\mathrm{a}}$ & NA & Guan et al., 2009 \\
\hline & 2006 & Peacock River & NA & NA & Chen et al., 2011 \\
\hline & $2007-2008$ & Songhua River & $1.1-14^{b}$ & NA & You et al., 2010 \\
\hline & 2007 & Dalio River estuary & NA & NA & Tan et al., 2009 \\
\hline Japan & $2002-2004$ & Kahokugata Lagoon and rivers & NA & $0.039-2.58$ & Kakimoto et al., 2006 \\
\hline Australia & 2006 & Sidney harbour & $0.021-0.54^{c}$ & $0.002-0.091$ & Roach et al., 2009 \\
\hline \multirow[t]{4}{*}{ USA } & $2002-2003$ & Houston ship channel & $0.49-12.49$ & NA & Howell et al., 2008 \\
\hline & 2008 & Houston ship channel & $0.46-69.1$ & NA & Lakshmanan et al., 2010 \\
\hline & 2004-2008 & Lake Ontario tributaries & $0.31-42.75$ & NA & Oliveira et al., 2011 \\
\hline & $2005-2006$ & Ballona creek, Los Angeles & $N D-34^{d}$ & NA & Curren et al., 2011 \\
\hline Swiss & 1994-1995 & Urban storm water & $N D-403^{e}$ & NA & Rossi et al., 2004 \\
\hline
\end{tabular}

\section{Keterangan:}

$\mathrm{ND}=$ Not detected $/$ tidak terdeteksi

NA $=$ Not available / tidak tersedia

$\Sigma$ PCBs = jumlah dari 209 PCBs isomer

${ }^{\mathrm{a}} \Sigma$ PCBs $=$ jumlah dari $20 \mathrm{PCBs}$ isomer

${ }^{\mathrm{b}} \Sigma \mathrm{PCBs}=$ jumlah dari $14 \mathrm{PCBs}$ isomer

${ }^{\mathrm{C}} \Sigma \mathrm{PCBs}=$ jumlah dari $12 \mathrm{PCBs}$ isomer

${ }^{\mathrm{d}} \Sigma \mathrm{PCBs}=$ jumlah dari $18 \mathrm{PCBs}$ isomer

${ }^{\mathrm{e}} \Sigma \mathrm{PCBs}=$ jumlah dari 7 PCBs isomer 